\title{
An exploration of fluoroscopically guided spinal steroid injections in patients with non-specific exercise-related lower-limb pain
}

This article was published in the following Dove Press journal:

Open Access Journal of Sports Medicine

18 September 2010

Number of times this article has been viewed

\author{
Leon Neve \\ John Orchard ${ }^{2}$ \\ Nathan Gibbs ${ }^{3}$ \\ Willem van Mechelen ${ }^{4}$ \\ Evert Verhagen ${ }^{4}$ \\ Ken Sesel ${ }^{5}$ \\ Ian Burgess ${ }^{6}$ \\ Brett Hines ${ }^{6}$ \\ 'VU University, Amsterdam, \\ The Netherlands; ${ }^{2}$ School of Public \\ Health, University of Sydney, Sydney, \\ NSW, Australia; ${ }^{3}$ South Sydney Sports \\ Medicine, Sydney, NSW, Australia; \\ ${ }^{4}$ EMGO, VU University, Amsterdam, \\ The Netherlands; ${ }^{5}$ Sydney X-ray \\ Centre, Sydney, NSW, Australia; \\ ${ }^{6}$ Mater Imaging, Sydney, NSW, \\ Australia
}

Correspondence: John Orchard Sports Medicine at Sydney University, CnrWestern Ave and Physics Rd, University of Sydney, NSW 2006, Australia Tel +6I 293518118

Fax $+6|2935| 8123$

Email johnworchard@gmail.com
Background: Fluoroscopically guided lumbar cortisone injections have been proven useful in cases of lower-limb pain caused by lumbar disc prolapse (with evidence levels 11-1/11-2). These injections are also sometimes used clinically in sports medicine for patients with non-specific exercise-related lower-limb pain, where no prolapse or other obvious cause of nerve-impingement is diagnosed via magnetic resonance imaging (MRI) or computed tomography (CT), even though this treatment scenario has not been adequately studied for this last diagnosis.

Objectives: To explore whether fluoroscopically guided transforaminal lumbar cortisone injections may be a valid treatment method for non-specific exercise-related lower-limb pain.

Study design: Retrospective case series.

Methods: Patients were selected from databases at two sports clinics and divided into two groups: Group D, with back-related lower-limb pain and disc prolapse proven on CT or MR; and Group N, with non-specific exercise-related lower-limb pain. Patients were sent a questionnaire regarding: symptoms, improvement, effect of injections, satisfaction, side effects and other used treatments. Outcomes were compared between Group D and N.

Results: 153 patients were eligible for the study (Group D: 93/Group N: 60). Eventually 110 patients responded (Group D: 67/Group N: 43). Twelve percent of Group D and 14\% of Group $\mathrm{N}$ indicated that the injections had fully cured their symptoms. Altogether, $27 \%$ of Group D and $24 \%$ of Group $\mathrm{N}$ were certain the injections had improved their symptoms in the long term. A larger proportion however, indicated that the injection had certainly improved their symptoms in the short term, but noted that the effects were non-lasting (Group D: 28\%/Group N: 30\%). Two patients were certain the injections had actually worsened their symptoms. No significant differences in characteristics and outcomes between Group D and Group N were noted.

Conclusions: Outcomes of this study suggest fluoroscopically guided lumbar cortisone injections may have similar outcomes in patients with non-specific exercise-related lower-limb pain compared to patients with disc prolapse proven on MRI or CT causing back-related lower-limb pain. This might suggest a potential role for these injections in the treatment of non-specific exercise-related lower-limb pain. It should be noted that this is a low level of evidence study (level 3) and further study is warranted.

Keywords: back-related lower-limb pain, fluoroscopically guided cortisone injections

\section{Introduction}

Exercise-related lower-limb pain, that is pain during or after exercise, is common in sport. On most occasions, a specific anatomical diagnosis of injury can be made in the lower-limb itself (eg, hamstring or calf pain proven to be a muscle strain on magnetic resonance imaging $[\mathrm{MRI}])$. However, some athletes and exercising individuals develop 
exercise-related lower-limb pain which is vague in nature and without specific pathology in the lower-limbs. ${ }^{1}$

In these cases, MRI or computed tomography (CT) of the lumbar spine sometimes reveals a disc prolapse. Although it is a controversial paradigm, as no specific mechanism has ever been proven for such an injury, many clinicians subscribe to the concept of a back-related hamstring injury as a cause of hamstring pain. ${ }^{1-3}$ When no specific pathology is found in the lower-limbs but prolapse is found on MRI/CT of the lower back, disc prolapse becomes the working diagnosis. For such cases, fluoroscopically guided cortisone injections around the lumbar nerve roots have shown to be helpful with evidence levels of 11-1 for short-term ( $<6$ months) and 11-2 for long-term (>6 months) relief. ${ }^{4,5}$

In a sports medicine setting in Australia, we have anecdotally experienced good clinical results using the same injections to the lumbar spine for the treatment of exercise-related lower-limb pain, including when prolapse or other definite cause of nerve-impingement was not established on MRI/CT. The symptoms may be caused by slight irritation of the nerve-roots by other tissues surrounding the nerve-root which is not shown on MRI/CT. This is interesting as despite no certain cause of nerve impingement being shown in the lumbar spine, treating the injury as a back-related condition has seemed to work in a fair number of cases.

While there remains no high-quality evidence to suggest that there is a valid link between this treatment and the success rate for this group of patients, in practice, our sports clinics have found that this treatment is quite successful. ${ }^{2}$ This needs further examination, which was the goal of this study: exploring whether fluoroscopically guided spinal steroid injections in patients with non-specific exercise-related lower-limb pain is similarly successful, compared to the same injections for a group of patients (with confirmed prolapse on MRI/CT) for which these injections have already been proven to be useful. As such, a purpose of this comparison was to explore whether fluoroscopically guided lumbar cortisone injections are potentially helpful for pain relief in patients with non-specific exercise-related lower-limb pain, in the medium to long term (>6 months).

\section{Methods}

This study was conducted as a retrospective case series. Patients were initially selected from the database of 2 Sydney based sports physicians if they had been referred for and received a fluoroscopically guided transforaminal lumbar cortisone at spinal levels from L3-4 to L5-S1 between
December 2002 and December 2007 for the treatment of lower-limb pain.

All of the injections (Figure 1) were performed by 1 of 3 radiologists at either Sydney X Ray or the Mater Hospital, both located in Sydney. Each of the radiologists had over 10 years of experience and used the same

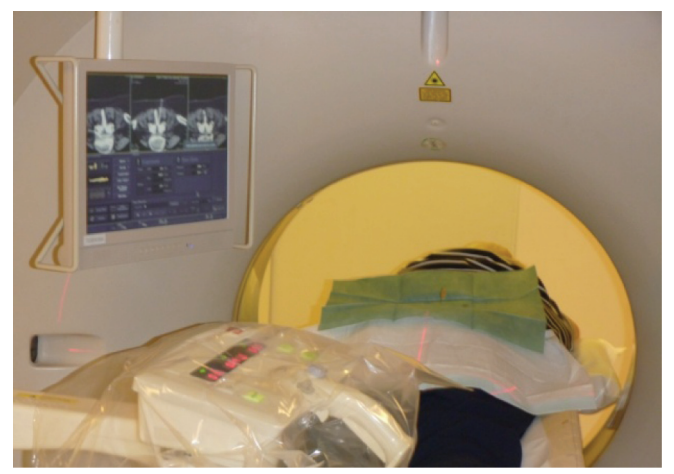

(A) Determination of appropriate needle position

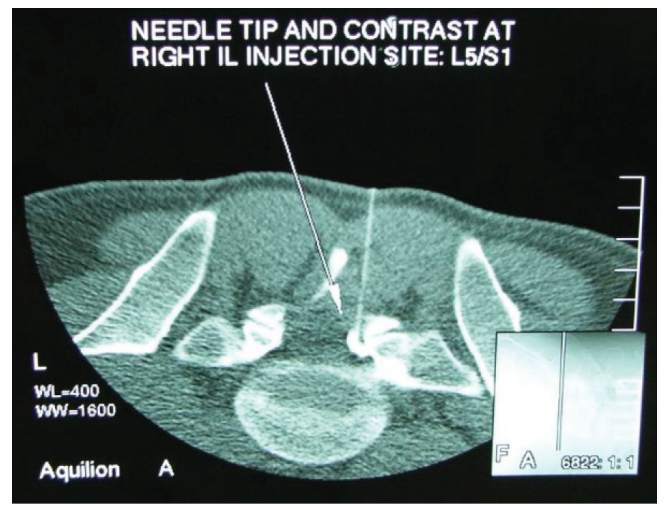

(B) Contrast injected and checked for appropriate spread

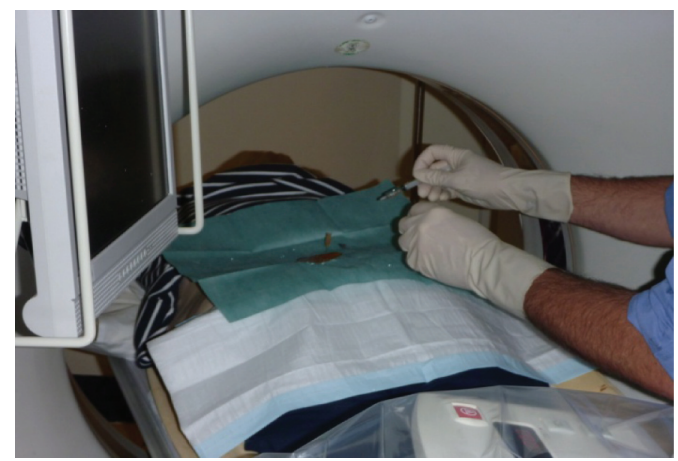

(C) Cortisone injection

Figure I The procedure. The injection procedure was performed in a sterile room. Local anesthesia was given before the actual injection. For the injection, a spinal needle was used under fluoroscopic guidance. The needle was placed in the superior and anterior aspect of the corresponding neuroforamen. After the needle was determined radiographically to be in the appropriate position $(\mathbf{A})$, contrast material was injected to document appropriate contrast spread along the spinal nerve into the epidural space without intravascular uptake (B). Next, a combination of cortisone with lidocaine was injected $(\mathbf{C})$. The determination in Figure $I(\mathbf{A})$ is done on the screen (which is shown) correlating with the needle tip (which cannot be seen in the picture and therefore arrowed, as it is too small). 
technology in conducting the procedure. Only patients referred by either of 2 sports physicians and treated by any of 3 radiologists were included to minimize inconsistency in the reason for referral and manner of injection technique.

December 2002 was chosen as the starting date for the cohort as this was the earliest date for which full computer records were available to check procedures conducted at the clinics. December 2007 was chosen as the end date to allow for a minimum of 12 months follow-up post-injection at the time of the start of the study.

Chart review was performed on the selected patients. The information collected included: patient characteristics (Table 1), specific lower-limb pathology, symptoms prior to the injections, and outcomes of MRI and CT scans including etiology of any sciatica (stenosis/prolapse/unknown) and level of pathology.

Patients under the age of 18 years old, or suffering a specific lower-limb pathology that was subsequently discovered on MRI or CT as being responsible for their pain, were excluded. The latter were excluded in order to keep the study focused specifically on cases with lower-limb pain presumably caused by pathology in the lower back. In this way, 153 patients were eligible for the study.

Patients were split based on chart and radiology review into Group D (95 patients) and Group N (58 patients). Group D consisted of patients whose primary diagnosis after lumbar MRI or CT scan was disc prolapse, presumed to be causing lower-limb pain. Group N consisted of patients whose primary diagnosis was non-specific exercise-related lower-limb pain; patients with suspected lower-back-related lower-limb pain but without prolapse on MRI or CT. Patients in Group N typically had vague exercise-related hamstring and/or calf pain.

Included patients were sent a questionnaire in December 2008 and were able to complete the questionnaire either on paper or on an internet site designed for this specific purpose. None of the patients who eventually replied objected to having their data used in our study. The study protocol was approved by the Human Ethics Research Committee of the University of Sydney.

The questionnaire was developed to assess several aspects of the medium-long-term effects of the injections. It comprised 7 multiple-choice questions with the possibility to file a written answer. Questions 1 and 2 related to specific symptoms in several areas of the lower-limbs and the lower back, while question 3 asked about the overall improvement of symptoms. Question 4 was designed to extract information on the extent to which the injections had a direct result on the improvement of symptoms. Question 7 asked whether the patients would have the same procedure done for the same symptoms, knowing what they now know. The answers to questions 3, 4 and 7 were combined to get a view on what the effect of the injections on the improvement of symptoms was, in the opinion of the patients. Question 5 asked whether side effects were experienced and question 6 aimed to exclude any other treatments that might have had an influence on the outcome of this study.

After collection and analysis of the answers, the improvement, the effect of the injections on the improvement, the satisfaction of the patients, side effects and other treatments could be compared between the main Groups ( $\mathrm{D}$ and $\mathrm{N}$ ) and between the subgroups: male/ female, elite/non-elite, and older/younger than 30 years of age.

The comparisons of answers to the questionnaire and of patient characteristics were done using Fisher's exact tests and two-tailed t-tests in setting significance at $P<0.05$. Online $\mathrm{GraphPad}^{\circ}$ software was used for this purpose.

\section{Results}

Initially 153 patients were selected for possible inclusion in this study: 93 in Group D (with proven disc prolapse on $\mathrm{MRI} / \mathrm{CT}$ ) and 60 in Group N (without disc prolapse shown

Table I Group comparisons between eligible patients and those successfully followed-up

\begin{tabular}{|c|c|c|c|c|c|c|c|c|c|}
\hline & \multicolumn{3}{|l|}{ Total } & \multicolumn{3}{|l|}{ Group D } & \multicolumn{3}{|c|}{ Group N } \\
\hline & $\begin{array}{l}\text { Initial } \\
\text { group } \\
(n=I 53)\end{array}$ & $\begin{array}{l}\text { Follow-up } \\
(\mathrm{n}=\mathrm{I} \mid 0)\end{array}$ & $P(+\mathrm{SE})$ & $\begin{array}{l}\text { Initial } \\
\text { group } \\
(n=93)\end{array}$ & $\begin{array}{l}\text { Follow-up } \\
(n=67)\end{array}$ & $P(+\mathrm{SE})$ & $\begin{array}{l}\text { Initial } \\
\text { group } \\
(n=60)\end{array}$ & $\begin{array}{l}\text { Follow-up } \\
(n=43)\end{array}$ & $P(+\mathrm{SE})$ \\
\hline Age (years) & 42.9 & 43 & $\begin{array}{l}0.21 \\
(0.95)\end{array}$ & 40.6 & 41 & $\begin{array}{l}0.85 \\
(2.05)\end{array}$ & 46.7 & 46 & $\begin{array}{l}0.79 \\
(2.63)\end{array}$ \\
\hline Male & II 0 (72\%) & 76 (69\%) & 0.59 & 67 (72\%) & $46(69 \%)$ & 0.90 & $43(72 \%)$ & $30(70 \%)$ & 1.00 \\
\hline Elite athlete & $54(35 \%)$ & $43(39 \%)$ & 0.61 & $33(36 \%)$ & $29(43 \%)$ & 0.55 & $21(34 \%)$ & 14 (33\%) & 1.00 \\
\hline Total number of athletes & II 8 (77\%) & $87(78 \%)$ & 0.88 & $70(75 \%)$ & $5 \mathrm{I}(76 \%)$ & 1.00 & $48(80 \%)$ & $36(84 \%)$ & 0.88 \\
\hline Length of follow-up (months) & 31.9 & 30.0 & $0.40(2.25)$ & 31.5 & 30.0 & $0.60(2.88)$ & 33.1 & 33.0 & $0.98(3.60)$ \\
\hline
\end{tabular}

Abbreviations: SD, standard deviation; SE, standard error. 
Table 2 Comparisons between the follow-up groups for patients with and without a disc prolapse on imaging

\begin{tabular}{llll}
\hline & $\begin{array}{l}\text { Group D } \\
(\mathbf{n}=\mathbf{6 7})\end{array}$ & $\begin{array}{l}\text { Group N } \\
(\mathbf{n}=\mathbf{4 3})\end{array}$ & $\begin{array}{l}\text { P-value } \\
\text { (SE) }\end{array}$ \\
\hline Age in years (mean \pm SD) & $41 \pm 12.8$ & $46 \pm 13.6$ & $0.05(2.56)$ \\
Male & $46(69 \%)$ & $30(70 \%)$ & 1.00 \\
Elite athlete & $29(43 \%)$ & $14(33 \%)$ & 0.32 \\
Total number of athletes & $51(76 \%)$ & $36(84 \%)$ & 0.47 \\
$\begin{array}{l}\text { Level of injection } \\
\quad \text { L3-L4 }\end{array}$ & $6(9 \%)$ & $2(4 \%)$ & 0.48 \\
$\quad$ L4-L5 & $27(40 \%)$ & $19(45 \%)$ & 0.70 \\
$\quad$ L5-SI & $34(51 \%)$ & $22(51 \%)$ & 1.00 \\
$\begin{array}{l}\text { Length of follow-up in months } \\
\text { (mean } \pm \text { SD) }\end{array}$ & $30 \pm 18$ & $33 \pm 18$ & $0.40(3.52)$ \\
\hline
\end{tabular}

Abbreviations: SD, standard deviation; SE, standard error.

or other obvious cause of nerve-impingement on MRI/CT). Follow-up was achieved for $71 \%$ of Group D (67 patients) and $74 \%$ of Group N (43 patients). Comparison of the full groups of those followed-up was made as no significant differences in characteristics were noted between the initial groups and the follow-up groups (Table 1).

Fisher's exact tests and unpaired t-tests showed no significant differences in most patient characteristics between Groups D and $\mathrm{N}$ after follow-up (Table 2). Age was 41 years \pm 12.8 (mean \pm standard deviation [SD]) in Group D and 46 years \pm 13.2 in Group N, which was significantly higher. The period of time between injection and follow-up was 30 months \pm 18 (mean \pm SD) for Group D and 33 months \pm 18 for Group N. Most injections were performed at $\mathrm{L} 5 / \mathrm{S} 1$ (51\% of the patients in both groups) and $\mathrm{L} 4 / 5(40 \%$ of patients in Group D and 45\% in Group N), and a small number at L3/4 (9\% in Group D and 3\% in Group N).
Several specific symptoms for Group D had decreased significantly, for Group $\mathrm{N}$ these symptoms had also decreased with quite high percentages, just not significantly. In decrease-rates, one significant difference was noted between Groups D and N; back pain during exercise had decreased significantly more in Group $\mathrm{D}(P=0.002)$. Hamstring pain during exercise, the symptom in the lower-limbs with the highest prevalence, had decreased significantly in both groups (Table 3).

No significant differences were found between Group D and $\mathrm{N}$ for patients opinions on: improvement of symptoms (Table 4), effect of injections on this improvement (Table 5) and whether they would have the same procedure done knowing what they now know (Table 6).

Almost one third of both groups (Group D: 28\%/Group N: $32 \%$ ) noted they were completely cured and exercising as much as before. Two other groups noted their symptoms were much better (Group D: 30\%/Group N: 16\%) and slightly better (Group D: $13 \% /$ Group N: $26 \%$ ). Overall symptoms of $71 \%$ of patients in Group D and $74 \%$ of patients in Group N were at least slightly better at the time of the questionnaire compared to just before injections. Eight percent of Group D and 7\% of Group $\mathrm{N}$ had no more pain but were not exercising as much as they used to. A fairly large group noted the symptoms were similar to before the injections (Group D: 16\% and Group N: $12 \%$ ) and a small percentage actually noted slight or much worsening of symptoms (respectively: Group D: $2 \% /$ Group N: $2 \%$ and Group D: 3\%/Group N: 5\%) (Table 4).

Twelve percent of Group D and 14\% of Group N were certain the actual injection had fully cured their condition. Another $15 \%$ of Group D and 9\% of Group N were certain the injections had improved their symptoms in the long term

Table 3 Specific symptoms before injections and at the time of questionnaire

\begin{tabular}{|c|c|c|c|c|c|c|c|c|}
\hline \multirow[t]{2}{*}{ Symptom } & \multicolumn{4}{|c|}{ Group D $(n=67)$} & \multicolumn{4}{|c|}{ Group $N(n=43)$} \\
\hline & Before & After & $P$-value & $\begin{array}{l}\text { Symptoms } \\
\text { resolved }\end{array}$ & Before & After & $P$-value & Decreased with \\
\hline Hamstring pain at rest & $24(36 \%)$ & $9(13 \%)$ & $0.0045^{*}$ & 15 (63\%) & 14 (33\%) & $6(14 \%)$ & 0.07 & $8(57 \%)$ \\
\hline Calf pain at rest & $12(18 \%)$ & $4(6 \%)$ & 0.06 & $8(67 \%)$ & $5(12 \%)$ & $2(5 \%)$ & 0.43 & $3(25 \%)$ \\
\hline Achilles/foot pain at rest & $10(15 \%)$ & 7 (10\%) & 0.61 & $3(30 \%)$ & $3(7 \%)$ & I (2\%) & 0.62 & $2(67 \%)$ \\
\hline Back pain at rest & 45 (67\%) & $28(42 \%)$ & $0.0053^{*}$ & $17(38 \%)$ & 21 (49\%) & 15 (35\%) & 0.27 & $6(29 \%)$ \\
\hline $\begin{array}{l}\text { Hamstring pain during } \\
\text { exercise }\end{array}$ & $30(45 \%)$ & $15(22 \%)$ & $0.01^{*}$ & $15(50 \%)$ & $19(44 \%)$ & $4(9 \%)$ & $0.0005^{*}$ & 15 (79\%) \\
\hline Calf pain during exercise & I4 (2 I\%) & $5(8 \%)$ & $0.0454^{*}$ & $9(64 \%)$ & $7(16 \%)$ & $2(5 \%)$ & 0.16 & $5(7 \mid \%)$ \\
\hline $\begin{array}{l}\text { Achilles/foot pain during } \\
\text { exercise }\end{array}$ & $10(15 \%)$ & $4(6 \%)$ & 0.16 & $6(60 \%)$ & $5(12 \%)$ & $2(5 \%)$ & 0.43 & $3(60 \%)$ \\
\hline Back pain during exercise & $38(57 \%)$ & $25(37 \%)$ & $0.04^{*}$ & $13(34 \%)$ & $17(40 \%)$ & $16(37 \%)$ & 1.00 & I (6\%) \\
\hline Numbness & $12(18 \%)$ & $7(10 \%)$ & 0.20 & $5(42 \%)$ & $7(16 \%)$ & $2(5 \%)$ & 0.16 & 5 (7।\%) \\
\hline Muscle weakness & $17(25 \%)$ & $6(9 \%)$ & $0.021^{*}$ & II (65\%) & $9(21 \%)$ & $5(12 \%)$ & 0.38 & $4(44 \%)$ \\
\hline Pins and needles & $17(25 \%)$ & $6(9 \%)$ & $0.021^{*}$ & II (65\%) & $8(19 \%)$ & $4(9 \%)$ & 0.35 & $4(50 \%)$ \\
\hline Other symptoms & $15(22 \%)$ & $9(13 \%)$ & 0.26 & $6(40 \%)$ & $10(23 \%)$ & $6(14 \%)$ & $0.4 I$ & $4(40 \%)$ \\
\hline
\end{tabular}

Note: "denotes statistically significant decrease after injection $(P<0.05)$. 
Table 4 Answers to question 3: How much better or worse are the symptoms now compared to just before the injection?

\begin{tabular}{|c|c|c|c|c|c|c|c|c|c|}
\hline & $\begin{array}{l}\text { Group D } \\
(n=67)\end{array}$ & $\begin{array}{l}\text { Group N } \\
(n=43)\end{array}$ & P-value & $\begin{array}{l}\text { Male } \\
(n=76)\end{array}$ & $\begin{array}{l}\text { Female } \\
(n=34)\end{array}$ & $P$-value & $\begin{array}{l}\text { Elite } \\
(n=43)\end{array}$ & $\begin{array}{l}\text { Non-elite } \\
(n=67)\end{array}$ & $P$-value \\
\hline $\begin{array}{l}\text { Completely cured and } \\
\text { exercising as before }\end{array}$ & $19(28 \%)$ & $14(32 \%)$ & 0.67 & $29(38 \%)$ & $4(12 \%)$ & $0.0 I^{*}$ & $18(42 \%)$ & $15(22 \%)$ & 0.04 \\
\hline $\begin{array}{l}\text { No pain but not exercising } \\
\text { as much }\end{array}$ & $5(8 \%)$ & $3(7 \%)$ & 1.00 & $5(7 \%)$ & $3(9 \%)$ & 0.70 & $3(7 \%)$ & $5(8 \%)$ & 1.00 \\
\hline Much better & $20(30 \%)$ & $7(16 \%)$ & 0.12 & $15(20 \%)$ & 12 (35\%) & 0.09 & $9(21 \%)$ & 18 (27\%) & 0.51 \\
\hline Slightly better & $9(13 \%)$ & II (26\%) & 0.13 & $15(20 \%)$ & $5(15 \%)$ & 0.60 & $6(14 \%)$ & 14 (21\%) & 0.45 \\
\hline Similar & II (16\%) & $5(12 \%)$ & 0.59 & $10(13 \%)$ & $6(18 \%)$ & 0.57 & $7(16 \%)$ & $9(13 \%)$ & 0.78 \\
\hline Slightly worse & I (2\%) & I (2\%) & 1.00 & I (I\%) & I (3\%) & 0.53 & $0(0 \%)$ & $2(3 \%)$ & 0.52 \\
\hline Much worse & $2(3 \%)$ & $2(5 \%)$ & 0.64 & I (I\%) & $3(9 \%)$ & 0.09 & $0(0 \%)$ & $4(6 \%)$ & 0.15 \\
\hline
\end{tabular}

Note: *denotes statistically significant decrease after injection $(P<0.05)$.

but did not fully cure them. Adding up, a fairly large group of patients (Group D: 27\%/Group N: 24\%) was certain the injections had improved their symptoms in the long term. Another $8 \%$ of Group D and 14\% of Group N thought the injections may have been helpful in the long term.

A similarly large proportion of patients who noted improvement indicated that the injection certainly had improved their symptoms, but noted that the effects had been non-lasting (Group D: 28\%/Group N: 30\%). Because of this only short-term lasting effect, one third would not have the procedure done for the same symptoms.

Another group (Group D 15\%/Group N: 12\%) thought the injections had played no role whatsoever in their improvement. Asked whether they would have the same procedure done, one third of these patients noticeably did answer yes. One person in Group D and one in Group N did report eventual improvement in symptoms but, despite this, thought the injections had actually worsened their symptoms.
Of the patients who thought their symptoms were unchanged (Group D: 16\%/Group N: 12\%), 50\% thought the injections had worked in the short term but that the effects were non-lasting (Group D: 6\%/Group N: 7\%). The patients who had worsening of symptoms did think the injections had worked for them but only in the short term. In the end, none of these patients blamed the injections for their worsening.

Importantly, as said before, no significant differences were noted between the main Groups D and N. Male and elite patients, however, answered significantly more often (with significance of respectively $P=0.01$ and $P=0.04$ ) that they were completely cured and were exercising as before and that their symptoms had improved. No significant difference was noted however in what they and their counter-subgroups thought about the effect of the injections on their improvement, or whether they would have the same procedure done for the same symptoms. Subgroups older/younger than 30 did not show any significant differences.

Table 5 Extent to which the injections contributed to improvement in patient groups with: "improvement of symptoms", "similar symptoms compared to before the injections", and "worsening of symptoms"

\begin{tabular}{|c|c|c|c|c|}
\hline & $\begin{array}{l}\text { Group D } \\
(n=67)\end{array}$ & $\begin{array}{l}\text { Group } N \\
(n=43)\end{array}$ & $\begin{array}{l}\text { P-value of } \\
\text { whole group }\end{array}$ & $\begin{array}{l}P \text {-value } \\
\text { intragroup }\end{array}$ \\
\hline 5.I Patients who noted improvement in symptoms: & $n=53(79 \%)$ & $\mathrm{n}=35(81 \%)$ & 0.81 & $X$ \\
\hline Completely cured as a result of injection & $8(12 \%)$ & $6(14 \%)$ & 0.78 & 1.00 \\
\hline Certain injection improved symptoms in long term & $10(15 \%)$ & $4(9 \%)$ & 0.56 & 0.39 \\
\hline Injection may have improved symptoms in long term & $5(8 \%)$ & $6(14 \%)$ & 0.33 & 0.53 \\
\hline Certain injection improved symptoms but effects were non-lasting & $19(28 \%)$ & $13(30 \%)$ & 0.83 & 0.83 \\
\hline Certain the Injection didn't do anything & $10(15 \%)$ & $5(12 \%)$ & 0.78 & 0.77 \\
\hline Injection may have worsened symptoms & I $(2 \%)$ & $0(0 \%)$ & 1.00 & 1.00 \\
\hline Certain injection worsened symptoms & $0(0 \%)$ & I (3\%) & 1.00 & 0.40 \\
\hline 5.2 Patients whose symptoms were similar to before injections: & $n=I \mid(16 \%)$ & $\mathrm{n}=5(12 \%)$ & 0.59 & $\mathrm{X}$ \\
\hline Certain injection improved symptoms but effects were non-lasting & $4(6 \%)$ & $3(7 \%)$ & 1.00 & 1.00 \\
\hline Certain the Injection didn't do anything & $7(10 \%)$ & $2(5 \%)$ & 0.48 & 1.00 \\
\hline 5.3 Patients whose symptoms had worsened: & $n=3(5 \%)$ & $n=3(7 \%)$ & 0.68 & $\mathrm{X}$ \\
\hline Certain injection improved symptoms but effects were non-lasting & $2(3 \%)$ & I $(2 \%)$ & 1.00 & 1.00 \\
\hline Certain the injection didn't do anything & I (2\%) & $2(5 \%)$ & 0.56 & 0.56 \\
\hline
\end{tabular}


Table 6 Answers to question 7: "would you have the same procedure done for the same symptoms knowing what you now know?"

\begin{tabular}{|c|c|c|c|c|c|c|c|c|c|}
\hline & $\begin{array}{l}\text { Group D } \\
(n=67)\end{array}$ & $\begin{array}{l}\text { Group N } \\
(n=43)\end{array}$ & $P$-value & $\begin{array}{l}\text { Male } \\
(n=76)\end{array}$ & $\begin{array}{l}\text { Female } \\
(n=34)\end{array}$ & P-value & $\begin{array}{l}\text { Elite } \\
(n=43)\end{array}$ & $\begin{array}{l}\text { Non-elite } \\
(n=67)\end{array}$ & P-value \\
\hline Yes, it was worth it & $43(64 \%)$ & $29(67 \%)$ & 0.84 & $53(70 \%)$ & $19(56 \%)$ & 0.20 & $30(70 \%)$ & $42(63 \%)$ & 0.54 \\
\hline No, because of expenses/side effects & $4(6 \%)$ & $0(0 \%)$ & 0.15 & $2(3 \%)$ & I $(3 \%)$ & 1.00 & $\mathrm{I}(2 \%)$ & $2(3 \%)$ & 1.00 \\
\hline No, because the effects didn't last very long & $7(10 \%)$ & $7(16 \%)$ & 0.78 & $9(12 \%)$ & $5(15 \%)$ & 0.76 & $3(7 \%)$ & II (I6\%) & 0.24 \\
\hline No because it was not helpful at all & $13(19 \%)$ & 7 (16\%) & 0.80 & $12(16 \%)$ & $9(27 \%)$ & 0.76 & $9(21 \%)$ & $12(18 \%)$ & 0.81 \\
\hline
\end{tabular}

Other factors which may have contributed to improvement were named by $61 \%$ of Group D and $47 \%$ of Group N. Most named treatments were physiotherapy (GroupD:40\%/Group N:42\%), massagetherapy(GroupD: 18\%/ Group N: 16\%) and chiropractic/osteopathy (Group D: 15\%/ Group N: 9\%).

One significant difference $(P=0.0007)$ was noted between Groups D and N: $19 \%$ of the patients with disc prolapse (Group D) went on to have surgery, compared to $5 \%$ in the group without disc prolapse (Group N) (Table 7). It is obvious that patients who went on to have surgery did so because symptoms did not improve after therapy with cortisone injections. A comparison between the group of patients who had undergone surgery after the injections and those who did not, confirmed this (Table 8). This might have had an influence on the eventual improvement of symptoms but not so much on what patients thought about the effect the injections had on this improvement.

Side effects were experienced by $70 \%$ of Group D and by $81 \%$ of Group N. No significant differences between Groups D and $\mathrm{N}$ were noted. The most common side effect was severe or moderate pain from injection (Group D: 22\%/ Group N: 14\%). Less common side effects were: muscle cramps, an affected regularity of menstruation cycle, headache, allergic reaction, dizziness, and sleepiness (Table 9).

\section{Discussion}

As MRI technology has improved over the past decades, an increasing number of hamstring injuries are being proven to in fact be muscle strains sited in the lower-limbs themselves. Despite this, there remain a significant number of suspected hamstring injuries that continue to be MRI-negative. ${ }^{1}$ Possible causes of the patient's pain in these circumstances include: extraforaminal entrapment of lumbosacral nerves, ${ }^{3}$ piriformis syndrome, ${ }^{6,7}$ and hamstring syndrome. ${ }^{8}$

Several other tissues surrounding the nerve-roots have the potential to cause nerve root impingement and inflammation in a similar way as a prolapsed disc can, as Briggs and Chandraraj showed for the lumbosacral ligament. ${ }^{12}$ The slightest irritation of the nerve roots may cause irritation and symptoms in the lower-limbs. This may not be detectable on MRI or CT and could therefore explain how the patients without prolapse or other obvious cause of nerve impingement on MRI/CT, and where no specific anatomical diagnosis of injury can be made in the lower-limb itself, do develop lower-limb pain. In some cases, nerve-impingement can be detected but no definite cause is shown (Figure 2). In the case of Figure 2, for example, it was thought by the clinicians that perhaps the thecal sac was being impinged by its expansion into the neural foramen, although this is speculative.

As pathology may be similar in patients with suspected back-related lower-limb pain, without prolapse or other obvious cause of nerve impingement shown on MRI/CT; and patients with assumed back-related lower-limb pain, with shown prolapse on MRI/CT, cortisone injections, which have been proven to be useful in the second group, may be just as useful in the group without shown prolapse. For this group, no definite help has been proven in earlier studies but good results have been

Table 7 Other treatments used

\begin{tabular}{lllll}
\hline Treatment & Group D (n= 67) & Group N (n= 43) & $P$-value & Total (n= I I 0) \\
\hline Physiotherapy & $27(40 \%)$ & $18(42 \%)$ & 1.00 & $45(41 \%)$ \\
Massage & $12(18 \%)$ & $7(16 \%)$ & 1.00 & $19(17 \%)$ \\
Chiropractic/osteopathy & $10(15 \%)$ & $4(9 \%)$ & 0.56 & $14(13 \%)$ \\
Surgery & $13(19 \%)$ & $2(5 \%)$ & $0.0007^{*}$ & $15(14 \%)$ \\
Other medication & $2(3 \%)$ & $0(0 \%)$ & 0.52 & $2(2 \%)$ \\
Cessation of aggravating activities & $6(9 \%)$ & $7(16 \%)$ & 0.36 & $13(12 \%)$ \\
Other & $15(22 \%)$ & $4(9 \%)$ & 0.12 & $19(17 \%)$ \\
Total number of patients receiving other treatments & $41(61 \%)$ & $20(47 \%)$ & 0.17 & $6 I(56 \%)$ \\
\hline
\end{tabular}

Note: "denotes statistically significant decrease after injection $(P<0.05)$. 
Table 8 Answers to question 7 "would you have the same procedure done for the same symptoms knowing what you now know?" for the "Surgery" and "No Surgery" groups

\begin{tabular}{lcll}
\hline & $\begin{array}{l}\text { Surgery } \\
(\mathbf{n}=15)\end{array}$ & $\begin{array}{l}\text { No surgery } \\
(\mathbf{n}=\mathbf{9 5})\end{array}$ & P-value \\
\hline $\begin{array}{l}\text { No, because it was not helpful } \\
\text { at all }\end{array}$ & $8(53 \%)$ & $13(14 \%)$ & $0.00^{*}$ \\
$\begin{array}{l}\text { No, because effects didn't last } \\
\text { very long }\end{array}$ & $3(20 \%)$ & II (12\%) & 0.40 \\
$\begin{array}{l}\text { No, because of expenses/side } \\
\text { effects }\end{array}$ & $0(0 \%)$ & $3(3 \%)$ & 1.00 \\
\begin{tabular}{l} 
Yes, because it was worth it \\
\hline
\end{tabular} & $4(27 \%)$ & $68(72 \%)$ & 0.003 \\
\hline
\end{tabular}

Note: "denotes statistically significant decrease after injection $(P<0.05)$.

experienced in practice in a sports medicine setting in Australia. Furthermore, for similar peripheral pathology as carpal tunnel syndrome ${ }^{13,14}$ and Morton's neuroma,${ }^{15}$ cortisone-injections have already shown to be helpful.

In this study no significant differences were found between the group with proven prolapse (Group D) and the group without proven prolapse or other obvious cause of impingement (Group N), in the way patients had improved, what effect the injections had had in this improvement, and whether they would have this injection done again for the same symptoms. Thirteen percent of the patients indicated the injections had completely cured their symptoms and altogether nearly one third of the patients were certain the injections had improved their symptoms in the long term. Another one third of all patients thought the symptoms certainly were affected, however only in the short term. This short term effect has been noted in other studies before. ${ }^{7}$ Two patients thought the injections had actually caused a temporary worsening in symptoms. The remaining patients did not notice any effect of the injections at all.

A significantly higher percentage of the "elite" and "male" subgroups were completely cured, and exercising as much as before, compared to the "non-elite" and "female" subgroups. The opinion however on the effect of injections on improvement and whether they would have the procedure done for the same symptoms again did not differ between these subgroups. Most of the elite athletes were in fact males $(79 \%)$ so the patients that caused this bias mainly belonged to one group; the male elite athletes. Possible reasons for these differences in outcome may be that elite athletes may get more medical attention and have better training and rehabilitation possibilities. As quite a large proportion of people in this study were elite athletes, this did probably influence the outcome. The percentage of elite athletes however was the same for Group D and N so this would not have influenced the comparison between Groups D and N.

This study was not a randomized control trial (RCT) but a retrospective case series and therefore does not have a very high level of evidence (level 3). Furthermore, follow-up time was quite spread out for this study. However, patients had the option to note they only had short-term effects. Patients who noted this had the same average follow-up time as the rest of the patients. Thirdly, all outcomes were based on opinions of the patients, so no detailed data on pain scores has been collected.

\section{Conclusion}

The most important aspect of the outcome of this study was that no significant differences were found between the group for which the injections have been proven to be helpful (Group D, with shown prolapse on MRI/CT) and the group for which this effect has not yet been proven (Group N, without shown prolapse or other obvious cause of nerve-impingement on MRI/CT),for improvement of symptoms. There was no difference between the groups for either symptom improvement, effect of injections on this improvement, and whether they would have the same procedure done again knowing what they now know.

This might suggest a potential role for the use of transforaminal corticosteroid injections for patients with nonspecific exercise-related lower-limb pain, without prolapse or other obvious cause of impingement shown on MRI/CT,

Table 9 Reported side effects

\begin{tabular}{lllll}
\hline & Group D (n= 67) & Group N (n= 43) & P-value & Total (n= I I0) \\
\hline None & $47(70 \%)$ & $35(81 \%)$ & 0.26 & $75 \%$ \\
Moderate pain from injection & $8(I 2 \%)$ & $5(I 1 \%)$ & 1.00 & $12 \%$ \\
Severe pain from injection & $7(10 \%)$ & $1(2 \%)$ & 0.15 & $7 \%$ \\
Allergic reaction & $1(2 \%)$ & $1(2 \%)$ & 1.00 & $2 \%$ \\
Sweating/dizziness & $\mathrm{I}(2 \%)$ & $\mathrm{I}(2 \%)$ & 1.00 & $2 \%$ \\
Headache & $\mathrm{I}(2 \%)$ & $0(0 \%)$ & 1.00 & $1 \%$ \\
Other & $6(9 \%)$ & $\mathrm{I}(2 \%)$ & 0.24 & $6 \%$ \\
\hline
\end{tabular}




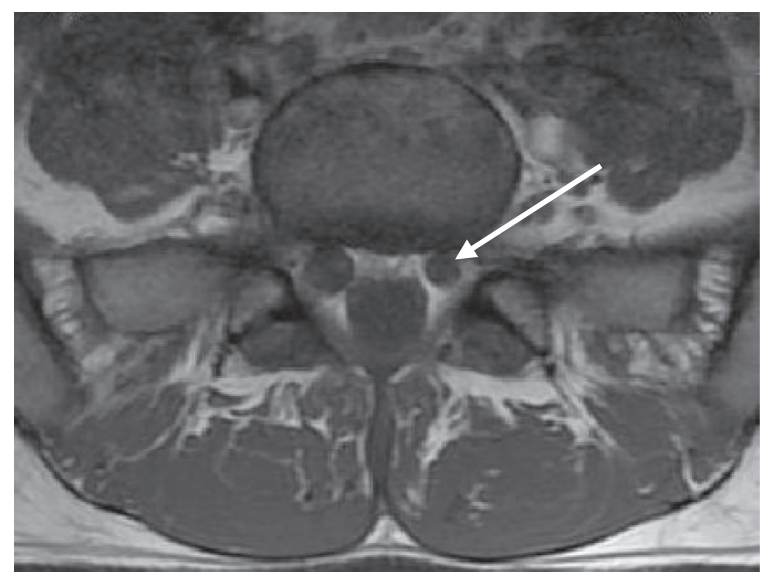

A MRI T1 L5/S1

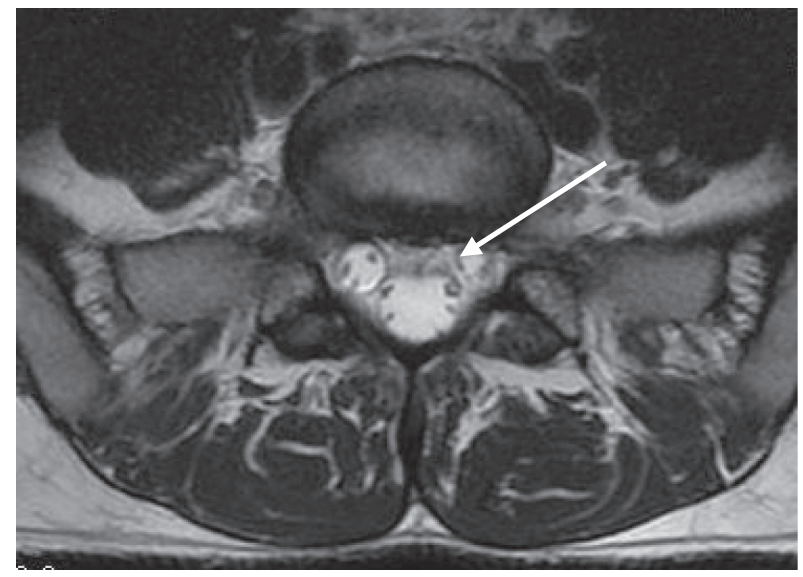

B MRI T2 L5/S1

Figure 2 Nerve impingement without prolapse on MRI. The arrow shows the nerve impingement in absence of a prolapse, as described.

and at least suggests more research should be done on this treatment for this specific cause.

Future studies on this subject should preferably be RCTs with a higher number of patients included. In this way the effect of this treatment for these specific symptoms can be more thoroughly investigated and actual conclusions drawn for future use of this treatment.

\section{Disclosure}

The authors report no conflicts of interest in this work other than the receipt of private consultation fees for treatment of patients in the study.

\section{References}

1. Verrall G, Slavotinek J, Barnes P, et al. Clinical risk factors for hamstring muscle strain injury: a prospective study with correlation of injury by magnetic resonance imaging. Br J Sports Med. 2001;35: 435-440.

2. Orchard J, Marsden J, Lord S, et al. Preseason hamstring muscle weakness associated with hamstring muscle injury in Australian footballers. Am J Sports Med. 1997;25:81-85.

3. Bennell K, Wajswelner $\mathrm{H}$, Lew P, et al. Isokinetic strength testing does not predict hamstring injury in Australian Rules footballers. Br J Sports Med. 1998;32:309-314.

4. Buenaventura RM, Datta S, Abdi S, et al. Systematic review of therapeutic lumbar transforaminal epidural steroid injections. Pain Physician. $2009 ; 12: 233-251$.
5. Lich LC, Sell P. Outcomes of a prospective cohort study on peri-radicular infiltration for radicular pain in patients with lumbar disc herniation and spinal stenosis. Eur Spine J. 2004;13:325-329.

6. Parziale JR, Hudgins TH, Fishman LM. The piriformis syndrome. Am J Orthop. 1997;26:316-318.

7. Boyajian-O’Neill LA, McClain RL, Coleman MK, et al. Diagnosis and management of piriformis syndrome: an osteopathic approach. J Am Osteopath Assoc. 2008;657-664.

8. Puranen J, Orava S. The hamstring syndrome - a new gluteal sciatica. Ann Chir Gynaecol. 1991;80:212-214.

9. Szalai K, Illyés A. Sacral epidural steroid injections used for the prevention of hamstring injuries. Physical Education and Sport. 2005;3:37-44.

10. Karppinen J, Ohinmaa A, Malmivaara A, et al. Cost effectiveness of periradicular infiltration for sciatica: subgroup analysis of a randomized controlled trial. Spine. 2001;26: 2587-2595.

11. Vad VB, Bhat AL, Lutz GE, et al. Transforaminal epidural steroid injections in lumbosacral radiculopathy: a prospective randomized study. Spine. 2002;27:11-16.

12. Briggs CA, Chandraraj S. Variations in the lumbosacral ligament and associated changes in the lumbosacral region resulting in compression of the fifth dorsal root ganglion and spinal nerve. Clin Anat. 1996;9:278-279.

13. Lee JH, An JH, Lee SH, et al. Effectiveness of steroid injection in treating patients with moderate and severe degree of carpal tunnel syndrome measured by clinical and electrodiagnostic assessment. Clin J Pain. 2009; 25:111-115.

14. Gurcay E, Unlu E, Gurcay A, et al. Evaluation of the effect of local corticosteroid injection and anti-inflammatory medication in carpal tunnel syndrome. Scott Med J. 2009;54:4-6.

15. Bennett GL, Graham CE, Mauldin DM. Morton's interdigital neuroma: a comprehensive treatment protocol. Foot Ankle Int. 1995;16:760-763.

\section{Publish your work in this journal}

Open Access Journal of Sports Medicine is an international, peer-reviewed, open access journal publishing original research, reports, reviews and commentaries on all areas of sports medicine. The manuscript management system is completely online and includes a very quick and fair peer-review system.

\section{Dovepress}

Visit http://www.dovepress.com/testimonials.php to read real quotes from published authors. 